\title{
Clinical pharmacology of exogenously administered alkaline phosphatase
}

\author{
P. Pickkers • F. Snellen • P. Rogiers • J. Bakker • \\ P. Jorens - J. Meulenbelt $\cdot$ H. Spapen - J. E. Tulleken • \\ R. Lins - S. Ramael • M. Bulitta - J. G. van der Hoeven
}

Received: 2 September 2008 /Accepted: 11 November 2008/Published online: 2 December 2008

(C) The Author(s) 2008. This article is published with open access at Springerlink.com

\begin{abstract}
Purpose To evaluate the clinical pharmacology of exogenous alkaline phosphatase (AP).

Methods Randomized, double-blind, placebo-controlled sequential protocols of (1) ascending doses and infusion duration (volunteers) and (2) fixed dose and duration (patients) were conducted at clinical pharmacology and intensive care units. A total of 103 subjects (67 male volunteers and 36 patients with severe sepsis) were administered exogenous, 10-min IV infusions (three ascending doses) or 24-72 $\mathrm{h}$ continuous (132.5-200 $\mathrm{U} \mathrm{kg}^{-1}$
\end{abstract}

P. Pickkers $(\bowtie) \cdot$ J. G. van der Hoeven

Department of Intensive Care Medicine (551),

Radboud University Nijmegen Medical Centre,

Geert Grooteplein 10, P. O. Box 9101, 6500HB Nijmegen,

The Netherlands

e-mail: p.pickkers@ic.umcn.nl

F. Snellen

Department of Anesthesiology, Isala Klinieken,

Zwolle, The Netherlands

\section{P. Rogiers}

Department of Intensive Care, Hospital Network Antwerp,

Antwerp, Belgium

\section{J. Bakker}

Department of Intensive Care, Erasmus Medical Centre,

Rotterdam, The Netherlands

P. Jorens

Department of Critical Care Medicine and Clinical Pharmacology, University Hospital Antwerp,

Antwerp, Belgium
$24 \mathrm{~h}^{-1}$ ) IV infusion with/without preceding loading dose and experimental endotoxemia for evaluations of pharmacokinetics, pharmacodynamics, safety parameters, antigenicity, inflammatory markers, and outcomes.

Results Linearity and dose-proportionality were shown during 10-min infusions. The relatively short elimination half-life necessitated a loading dose to achieve stable enzyme levels. Pharmacokinetic parameters in volunteers and patients were similar. Innate immunity response was not significantly influenced by AP, while renal function significantly improved in sepsis patients.

\author{
J. Meulenbelt \\ Division of Intensive Care Centre, \\ University Medical Centre Utrecht, \\ Institute for Risk Assessment Sciences, \\ Utrecht University, \\ Utrecht, The Netherlands \\ H. Spapen \\ ICU Department, University Hospital, \\ Vrije Universiteit, \\ Brussels, Belgium \\ J. E. Tulleken \\ Intensive and Respiratory Care Unit, \\ University Medical Centre, \\ Groningen, The Netherlands \\ R. Lins $\cdot$ S. Ramael \\ Clinical Pharmacology Unit Antwerp, \\ SGS Life Science Services, \\ Antwerp, Belgium \\ M. Bulitta \\ CRM Biometrics GmbH, \\ Rheinbach, Germany
}


Conclusions The pharmacokinetics of exogenous AP is linear, dose-proportional, exhibit a short half-life, and are not influenced by renal impairment or dialysis.

Keywords Alkaline phosphatase - Clinical trial . Inflammation $\cdot$ Volunteer $\cdot$ Sepsis $\cdot$ Renal failure

\section{Introduction}

Alkaline phosphatases (APs) are dimeric enzymes that are highly prevalent in nature [1], from bacteria [2] to marine life [3] to mammals [4]. In man, AP is present in many cells and organs (e.g., intestines, kidney, placenta, liver, bone, neutrophils) [5]. Although the dephosphorylating properties of AP are well characterized [6,7], its role is not fully elucidated. A growing body of evidence suggests that AP plays an important part in host defense in dephosphorylating extracellular ATP $[8,9]$, a known pro-inflammatory molecule, into adenosine, a key molecule in tissue protection mechanisms [10], while extracellular ATP is also involved in the activity of phosphatases and phosphodiesterases [11]. This ecto-enzyme also plays an important role against inflammatory reactions due to lipopolysaccharide (LPS endotoxin) release during bacterial infection [12, 13].

Prior to large trials testing the role of exogenously administered AP enzyme in tissue protection during inflammation such as in cases of sepsis and inflammatory bowel disease, it is paramount to characterize the clinical pharmacology of exogenously administered enzyme.

We have conducted three sequential protocols with AP in humans to evaluate the pharmacokinetics and pharmacodynamics parameters of intravenously (IV) administered enzyme. The three sequential studies were randomized and placebo-controlled, and evaluated the main clinical pharmacology and safety parameters of exogenous AP in the presence and absence of experimental human endotoxemia in volunteers and in patients with severe sepsis.

\section{Methods}

The three protocols were conducted sequentially and included a total of 103 subjects. The dosing escalation schedules displayed in Table 1 (placebo: $n=28$; AP: $n=75$ ) proceeded as follows: study A: short, 10-min IV administration of ascending AP doses (groups 1-4) and 24-h IV administration (group 5) in healthy volunteers; study B: 24to 72-h IV administration with and without initial 10-min AP loading dose (groups 6-8) in healthy volunteers; and study C: $24-\mathrm{h}$ IV administration preceded by $10-\mathrm{min}$ AP loading dose in sepsis patients. Studies A and B also included three groups (Table 1: groups 4, 6, and 7) subjected to experimental endotoxemia for pharmacodynamics evaluation.

Methods, blinding and subject selection

The first two studies (A and B) were conducted in volunteers, both were randomized and placebo-controlled, with 67 subjects enrolled in total (placebo: $n=17$; AP: $n=$ 50). The studies were conducted at the Clinical Pharmacology Unit Antwerp (Belgium), with prior approval by the appropriate institutional review board (IRB; Commissie Voor Medische Ethiek - OCMW Antwerpen). Entry criteria were identical for studies A and B, namely males aged 1850 years and considered healthy during medical screening by a qualified physician, based on medical history, physical examination, body mass index (BMI) $18-28 \mathrm{~kg} / \mathrm{m}^{2}$, vital signs, blood and urine evaluations, and 12-lead electrocardiogram (ECG). All volunteers provided written informed consent, and the studies were conducted in compliance with current Guidelines on Good Clinical Practice [14], between January and June 2003 (study A) and November 2003 and September 2004 (study B). The aims of both studies were to evaluate the safety, pharmacokinetics, and pharmacodynamics of IV administration of exogenous AP. Safety parameters included tracking adverse events, vital signs, and changes in ECG, hematology, clinical chemistry, urinalysis, and immunogenicity. Pharmacokinetics (PK) parameters were maximum concentration $\left(\mathrm{C}_{\max }\right.$ expressed as serum enzyme activity corrected for baseline level), area under the plasma activity curve (AUC), clearance (CL/ $\left.1.73 \mathrm{~m}^{2}\right)$, and elimination half-life $\left(\mathrm{t}_{1 / 2}\right.$ measured as time to achieve $50 \%$ or lower activity of the point of enzyme activity equilibrium, the latter being the level at the end of the short 10-min infusion, or the level at the end of the 24to 72 -h infusions).

In two groups receiving short infusions (groups 4 and 7) and in one group receiving 72-h infusion (group 6), the volunteers were challenged with LPS endotoxin of 2-min duration given intravenously 2 min after starting the short AP infusion or given $2 \mathrm{~h}$ after starting the $72-\mathrm{h}$ AP infusion, to evaluate safety and pharmacodynamics (Table 1). Samples for PK were taken for groups 1-3 (short 10-min administration in volunteers) at baseline, 5, 10, 20, 30, 45, 60 , and $90 \mathrm{~min}$ and 2, 4, and $8 \mathrm{~h}$. Sampling times for the 24-h infusion in volunteers (group 5) were at baseline, 10, 20, 30, 45, and $60 \mathrm{~min}$ and 4 and $24 \mathrm{~h}$ and then, after the end of infusion, at 10, 15, 20,30, 45, and $60 \mathrm{~min}$ and 2, 4, and $8 \mathrm{~h}$. Sampling times for the 72-h infusion in volunteers (group 8) were at baseline, 10, 30, and $60 \mathrm{~min}$ and 1.5, 2, 3, $4,6,8,12,24,36,48$, and $72 \mathrm{~h}$ and then, after the end of infusion, at 10, 20, 30, 45, and $60 \mathrm{~min}$ and 2, 3, 4, 5, 6, and $7 \mathrm{~h}$. Owing to endogenous enzyme levels playing a 
Table 1 Sequential dosing schedule in studies A, B, and C

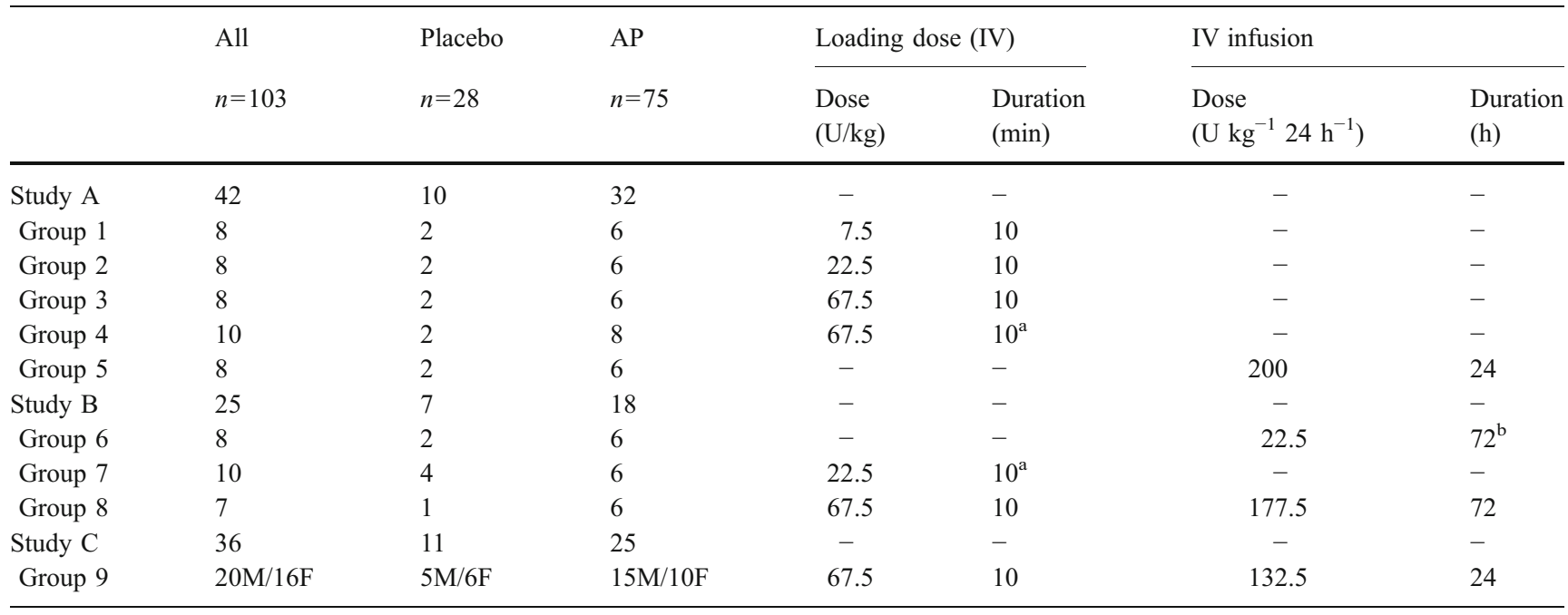

Studies A and B were in male healthy volunteers; study $\mathrm{C}$ was in sepsis patients of both genders ( $M$ males, $F$ females)

${ }^{a}$ Administration of IV LPS (E. coli EC6, $4 \mathrm{ng} / \mathrm{kg}$ ) for 2 min after 2 min AP infusion start

${ }^{\mathrm{b}}$ Administration of IV LPS (E. coli EC6, $4 \mathrm{ng} / \mathrm{kg}$ ) for 2 min after $2 \mathrm{~h}$ AP infusion start

proportionally larger role in low-dose, short infusions, the elimination half-life was planned to be re-evaluated during long infusions with the addition of multiple samplings at the end of AP infusions in groups 5 and 8 .

The third protocol (study C) was conducted in patients with severe sepsis. The study was randomized and placebocontrolled and enrolled 36 patients (ratio 1:2; placebo: $n=$ 11; AP: $n=25$ ) (Table 1) between September 2004 and March 2006 at eight intensive care units (ICU) in The Netherlands and Belgium, with prior approval by the institutional review board of each hospital and written informed consent of the patient or next-of-kin. Study conduct was in compliance with current Guidelines on Good Clinical Practice [14]. Study C was conducted after European central trial registration was in place and was centrally registered (EUDRACT: 2005-005257-21). Entry criteria were males/females aged 18-80 years with proven or suspected Gram-negative bacterial infection, at least two of four Systemic Inflammatory Response Syndrome (SIRS) criteria for under $24 \mathrm{~h}$ and acute-onset end-organ failure [15] in the preceding $12 \mathrm{~h}$, including hypotension requiring vasopressor therapy. Exclusion criteria were life-expectancy less than $24 \mathrm{~h}$, chronic renal failure, acute pancreatitis with no established source of infection, HIV infection, pregnancy or lactation, confirmed Gram-positive or fungal sepsis, or use of aminoglycoside antibiotics, immunosuppressants, or high-dose corticosteroids $\left(\geq 1 \mathrm{mg} \mathrm{kg}^{-1}\right.$ day $^{-1}$ prednisone equivalent).

The aims of study $\mathrm{C}$ were to evaluate the safety, pharmacokinetics, and pharmacodynamics of 24-h IV administration (fixed dose: 10-min IV loading followed by 24-h IV infusion) of exogenous AP in sepsis patients with end-organ dysfunction. Safety parameters included tracking adverse events, vital signs, and changes in ECG, hematology, clinical chemistry, urinalysis, renal parameters, and immunogenicity. Pharmacokinetics parameters were $C_{\max }$ (corrected for baseline level), AUC, clearance (CL/ $\left.1.73 \mathrm{~m}^{2}\right)$, and elimination half-life $\left(\mathrm{t}_{1 / 2}\right.$ measured as time to achieve $50 \%$ or lower activity at the point of enzyme activity equilibrium, the latter being the mean activity level between 18 and $24 \mathrm{~h}$ from infusion start). The sampling times for PK in patients (group 9) were at baseline, 10, 30, and $60 \mathrm{~min}$ and 1.5, 6, 18, and $24 \mathrm{~h}$ and then, after the end of infusion, at 4,8 , and $24 \mathrm{~h}$.

Blinding in all studies was assured by central allocation of randomization codes in sealed envelopes, audited on completion of each study, and by supply of study medication in indistinguishable form (placebo consisted of same volume, identical appearance, and excipients, except the enzyme).

For pharmacodynamics evaluations, cytokine measurements [IL-1 $\beta$, IL-6, IL-8, IL-10, TNF $\alpha$, and granulocytemacrophage colony-stimulating factor (GM-CSF)] were analyzed centrally by Xendo Biodevelopment Laboratories (Groningen, The Netherlands) using validated assays for each cytokine. Antibodies to exogenous AP were measured centrally by TNO Quality of Life Laboratories (Zeist, The Netherlands) as total immunoglobulins (Ig), total IgE, and specific IgG-anti-AP by validated enzymelinked immunosorbent assay (ELISA), at baseline, 14, and 21 days post-dosing in volunteers, and at baseline, 14 , and 21 days post-dosing in sepsis patients. Skin-prick tests for sensitization were conducted in studies A and B (volunteers), with the reaction measured as wheal diameter $(+$ to ++++$)$ 
tested for AP, for AP buffer solution, and for two controls (one negative: $\mathrm{NaCl}$; one positive: histamine). AP enzyme activity evaluation was by specific kinetic assay described by Beumer [16].

Study medication (active and placebo) was supplied by AM-Pharma BV, The Netherlands, as calf-intestinal alkaline phosphatase in glycerol solution (CAS Registry: EC 3.1.3.1) in $1-\mathrm{mL}$ vials containing AP $5,000 \mathrm{U} / \mathrm{mL}$, complying with the European Union's guidelines on minimization of bovine spongiform encephalopathy (BSE) risk in medicine manufacture [17], approved by the national medicines regulatory authority.

Statistics, assignment, and analysis

In each study, randomized treatment allocation was sequential. Randomization lists were issued as single blocks of eight (two placebo; six active) for groups 1, 2, 3, 5, 6, and 8 and in single blocks of 10 (two placebo; eight active) for groups 4 and 7 , in studies A and B. For study C, randomization was in blocks of three with complete blocks assigned to each ICU. The intention-to-treat (ITT) population for safety evaluations was defined in all studies as all randomized subjects who received any medication. For the pharmacokinetics analyses, subjects without a baseline value for AP activity were excluded from all kinetic calculations. Full datasets were obtained for PK evaluations from the volunteers in studies A and B, except for one volunteer in group 8 (study B). In study C, 11 complete patient datasets were available for PK evaluations, while safety data were complete for all 36 patients.

Owing to the expected presence of renal failure in approximately $50 \%$ of sepsis patients and dialysis being a common intervention with an unknown effect on drug metabolism, pharmacokinetics was evaluated according to presence/absence of renal failure and/or dialysis, separately. In patients with renal failure, urinary markers of renal injury [nitrous oxide (NO) metabolites and glutathione-Stransferase-A1-1 (GSTA1-1)] were also evaluated. The sample size for the sepsis study had to be increased substantially relative to normal volunteers to obtain a minimum of six complete datasets for pharmacokinetics evaluations in sepsis with renal failure, estimated as a minimum of $30 \%$ of severe sepsis, to allow meaningful comparisons with volunteers, and hence a minimum of 36 patients in total were needed for a 2:1 randomization ratio. All data for the three studies were centrally analyzed by CRM Biometrics, Rheinbach, Germany, using SAS (version 8.2, SAS Institute, Cary, NC, USA; with PROC Means, Tabulate, Univariate, and Freq, validated against reference data where appropriate), or WinNonLin Professional (Pharsight) version 4.0. Means, standard deviations, medians, ranges, and upper and lower quartiles were calculated. Pharmacokinetics parameters were listed by subject, summarized, and evaluated using descriptive statistics.

\section{Results}

Subjects' characteristics and progress through studies

Dosing schedules are displayed in Table 1 and demographics data for all three studies at entry are displayed in Table 2. Owing to limited space, a large volume of data and the volunteer groups being narrowly defined, the demographic data are presented as combined AP and placebo groups for studies A and B. One volunteer randomized to group 8 (study B; Table 1) tested positive for benzodiazepines during screening before receiving study medication and was not replaced. All other volunteers in groups 1-8 received study medication as planned and yielded complete datasets for safety and other analyses. Groups 4, 6 , and 7 were planned for safety and pharmacodynamics evaluations of exogenous AP enzyme during systemic inflammation induced by experimental endotoxemia, as these data were required for subsequent studies in sepsis patients who have large amounts of circulating bacterial endotoxins.

Pharmacokinetics in healthy volunteers

Demographic data on volunteers are presented in Table 2, combined for studies A and B as the entry criteria were identical. Dose proportionality and linearity in pharmacokinetics of exogenous intravenous AP were examined

Table 2 Entry demographic data in studies A and B (healthy volunteers) and C (sepsis patients)

\begin{tabular}{|c|c|c|c|c|c|c|}
\hline & \multirow{2}{*}{\multicolumn{2}{|c|}{$\begin{array}{l}\text { Healthy } \\
\text { volunteers } \\
(n=67)\end{array}$}} & \multicolumn{4}{|c|}{ Patients $(n=36)$} \\
\hline & & & \multicolumn{2}{|c|}{$\begin{array}{l}\text { Placebo } \\
(n=11)\end{array}$} & \multicolumn{2}{|c|}{$\begin{array}{l}\text { AP } \\
(n=25)\end{array}$} \\
\hline & Mean & SD & Mean & SD & Mean & SD \\
\hline Age (years) & 36.8 & 8.1 & 55.7 & 18.3 & 58.7 & 16.6 \\
\hline Height $(\mathrm{cm})$ & 180.6 & 7.5 & 172.2 & 9.4 & 172.8 & 9.3 \\
\hline Weight (kg) & 77.4 & 9.5 & 78.6 & 14.4 & 76.5 & 17.8 \\
\hline BMI $\left(\mathrm{kg} / \mathrm{m}^{2}\right)$ & 23.8 & 2.2 & 26.6 & 4.9 & 25.8 & 6.2 \\
\hline $\begin{array}{l}\text { Systolic BP } \\
(\mathrm{mmHg})\end{array}$ & 119.6 & 11.2 & 110.3 & 17.4 & 104.6 & 18.4 \\
\hline $\begin{array}{c}\text { Diastolic BP } \\
(\mathrm{mmHg})\end{array}$ & 73.6 & 7.7 & 61.6 & 7.1 & 54.7 & 9.6 \\
\hline Heart rate (bpm) & 61.0 & 8.9 & 109.4 & 25.6 & 107.2 & 26.6 \\
\hline
\end{tabular}

$B M I$ Body mass index, $B P$ blood pressure 
during 10-min infusions of trebling ascending doses in groups $1-3(7.5,22.5$, and $67.5 \mathrm{U} / \mathrm{kg}$ total dose, respectively) administered sequentially to eight (six active; two placebo) volunteers in each group. Using serum enzyme activity levels for calculations in a one-compartmental model, the results suggest that $\mathrm{C}_{\max }$ (Fig. 1 and Table 3) showed proportionality within the dose range, while the AUC data also suggest linearity for the three doses. Elimination half-life $\left(\mathrm{t}_{1 / 2}\right)$ and drug clearance were calculated but, as previously mentioned (see "Methods"), the long-infusion data from volunteers were better predictors of patient data.

The next group in the dose escalation (group 5) received a continuous, 24-h infusion of $200 \mathrm{U} / \mathrm{kg}$ (total dose). Main PK parameters for group 5 are presented in Table 3 and Fig. 2a, where AUC values in particular led to the conclusion that a loading dose would be necessary to attain relatively stable plasma activity of approximately double the baseline (endogenous) values (mean baseline AP for volunteers was $74 \mathrm{U} / \mathrm{L}$ ). Estimated mean elimination halflife for group 5 was $11.9 \mathrm{~h}$ with a fast elimination phase after discontinuation of infusion, while mean clearance was 7.2 L/h. Although the data may suggest a long, second elimination phase, this was influenced by food intake, which increases endogenous enzyme activity, and it was impossible to demand near-fasting conditions from volunteers beyond $24 \mathrm{~h}$.
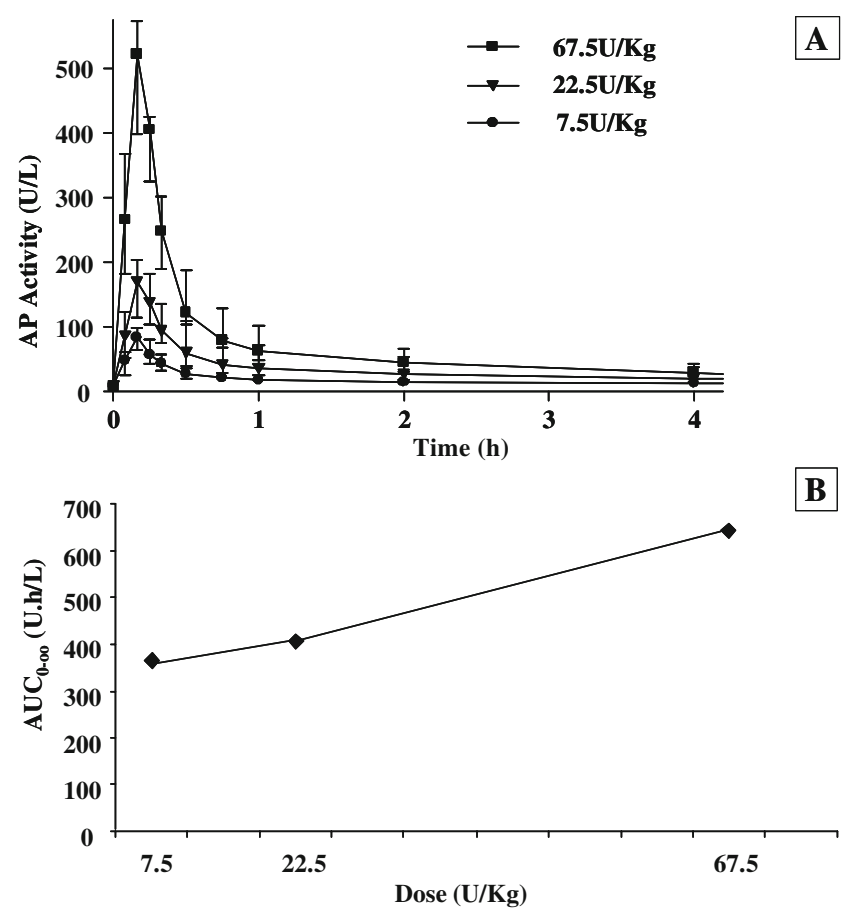

Fig. 1 Dose-proportionality and linearity (10-min infusion). a Serum activity data points are medians and interquartile ranges. b Area under the curve (AUC) data points are arithmetic means
The next group of dose escalation (group 8) for PK evaluations received an initial 10-min loading dose of 67.5 U/kg followed by continuous infusion of $177.5 \mathrm{U} \mathrm{kg}^{-1}$ $24 \mathrm{~h}^{-1}$ for $72 \mathrm{~h}$. Mean $\mathrm{C}_{\max }$ values reflected the loading dose (group 8, Table 3 and Fig. 2b). The results for group 8 highlight the difficulties in evaluating pharmacokinetics of AP enzyme: the median $C_{\max }$ for group 8 was $55 \%$ lower than for group 3 despite both groups having the same demographic characteristics and having received the same dose for the first 10 min. Mean and median $\mathrm{AUC}_{0-24}$ were very similar and served as a basis for subsequent comparative kinetics in patients. Elimination half-life was approximately $8 \mathrm{~h}$ and mean enzyme clearance was $4.7 \mathrm{~L} / \mathrm{h}$. The results for group 8 confirmed that a loading dose would be needed to attain higher stable levels of enzyme activity in the following patient study.

\section{Pharmacokinetics in sepsis patients}

Sepsis patients (group 9) received a 10-min loading dose of $67.5 \mathrm{U} / \mathrm{kg}$ followed by continuous infusion of $132.5 \mathrm{U} / \mathrm{kg}$ for $24 \mathrm{~h}$. All PK parameters were evaluated for the three sepsis subgroups, namely, patients without acute renal failure and not on renal replacement therapy (RRT; dialysis) (group 9.1;n=5), patients with renal failure without RRT (group 9.2; $n=4$ ), and patients with renal failure on RRT (group 9.3; $n=2$ ) (Table 3 ). There were no significant differences in any of the main PK parameters across patient groups.

Although there were only two patients receiving RRT (group 9.3), no major differences were detected relative to those without acute renal failure or with acute renal failure not on RRT. Mean $\mathrm{C}_{\max }$ reflected the loading dose in the three sepsis sub-groups (range of means: 246-317 U/L), very similar to values obtained in group 8 (volunteers), who had received an identical loading dose. $\mathrm{AUC}_{0-24}$ in patients (range of medians: 1,063-1,121 $\mathrm{U} \mathrm{h}^{-1} \mathrm{~L}^{-1}$ ) was comparable to volunteers in group 8 (median: 1,105 $\mathrm{U} \mathrm{h}^{-1} \mathrm{~L}^{-1}$ ). Enzyme clearance was 7.0-7.5 L/h across patient subgroups. Overall, the patient data were within the overall variability range of volunteers.

Samples at three time-points post-treatment (4, 8, $24 \mathrm{~h})$ were collected for estimation of whether elimination $t_{1 / 2}$ had been achieved at these points, defined as activity level $\leq 50 \%$ of mean activity at $18-24 \mathrm{~h}$ infusion. Elimination $\mathrm{t}_{1 / 2}$ was $\leq 4 \mathrm{~h}$ for one patient, $4-8 \mathrm{~h}$ for six patients, and slightly longer than $8 \mathrm{~h}$ for four patients, similar to volunteers in groups 5 and 8 who had received $\geq 24 \mathrm{~h}$ infusion and for whom we had robust elimination data. Regardless of the parameter, the patient data did not suggest that the pharmacokinetics of exogenous AP is affected in any appreciable manner by the profound metabolic abnormalities that accompany severe sepsis, 
Table 3 Pharmacokinetics parameters of exogenously administered AP

\begin{tabular}{|c|c|c|c|c|c|c|c|c|c|}
\hline & & \multicolumn{3}{|c|}{$\begin{array}{l}\text { 10-min infusion } \\
\text { (volunteers) }\end{array}$} & \multicolumn{2}{|c|}{$\begin{array}{l}\geq 24 \text {-h infusion } \\
\text { (volunteers) }\end{array}$} & \multicolumn{3}{|l|}{$\begin{array}{l}\text { 24-h infusion } \\
\text { (sepsis patients) }\end{array}$} \\
\hline & & $\begin{array}{l}\text { Group } 1 \\
(n=6)\end{array}$ & $\begin{array}{l}\text { Group } 2 \\
(n=6)\end{array}$ & $\begin{array}{l}\text { Group } 3 \\
(n=6)\end{array}$ & $\begin{array}{l}\text { Group } 5 \\
(n=6)\end{array}$ & $\begin{array}{l}\text { Group } 8 \\
(n=5)\end{array}$ & $\begin{array}{l}\text { Group 9.1: no ARF, } \\
\text { no dialysis }(n=5)\end{array}$ & $\begin{array}{l}\text { Group 9.2: ARF, } \\
\text { no dialysis }(n=4)\end{array}$ & $\begin{array}{l}\text { Group 9.3: ARF, } \\
\text { on dialysis }(n=2)\end{array}$ \\
\hline \multirow[t]{5}{*}{$\mathrm{C}_{\max }(\mathrm{U} / \mathrm{L})$} & Mean & 82.8 & 167.3 & 501.2 & 61.8 & 272.4 & 275.1 & 245.8 & 317.1 \\
\hline & $\mathrm{SD}$ & 17.4 & 45.6 & 86.6 & 13.2 & 33.4 & 110.4 & 51.2 & 101.9 \\
\hline & Median & 84.0 & 179.6 & 522.4 & 56.0 & 290.4 & 273.5 & 240.2 & 317.1 \\
\hline & Min & 62.4 & 95.2 & 346.4 & 50.7 & 219.3 & 132.1 & 189.3 & 245.0 \\
\hline & $\operatorname{Max}$ & 111.2 & 216.0 & 578.4 & 85.0 & 299.4 & 440.9 & 313.4 & 389.1 \\
\hline \multirow[t]{5}{*}{$\mathrm{AUC}_{0-24}(\mathrm{U} \cdot \mathrm{h} / \mathrm{L})$} & Mean & - & - & - & $1,282.3$ & $1,084.3$ & $1,122.3$ & $1,267.4$ & $1,063.4$ \\
\hline & SD & - & - & - & 345.3 & 167.4 & 347.5 & 272.0 & 98.6 \\
\hline & Median & - & - & - & $1,147.7$ & $1,105.1$ & $1,121.5$ & $1,107.0$ & $1,063.4$ \\
\hline & Min & - & - & - & $1,022.7$ & 920.2 & 627.9 & $1,026.6$ & 993.7 \\
\hline & Max & - & - & - & $1,914.0$ & $1,330.4$ & $1,519.9$ & $1,659.5$ & $1,133.2$ \\
\hline \multirow[t]{5}{*}{$\mathrm{AUC}_{0-\mathrm{oo}}(\mathrm{U} \cdot \mathrm{h} / \mathrm{L})$} & Mean & 364.4 & 405.7 & 642.5 & $2,005.1$ & $3,472.8$ & $1,911.9$ & $2,134.2$ & $1,832.3$ \\
\hline & $\mathrm{SD}$ & 175.7 & 176.5 & 192.4 & 375.7 & 574.9 & 453.6 & 332.1 & 286.1 \\
\hline & Median & 330.9 & 367.9 & 588.0 & $1,972.7$ & $3,484.1$ & $2,011.0$ & $2,014.3$ & $1,832.3$ \\
\hline & Min & 163.1 & 265.2 & 469.5 & $1,396.0$ & $2,913.6$ & $1,425.8$ & $1,901.9$ & $1,630.0$ \\
\hline & $\operatorname{Max}$ & 695.0 & 754.6 & 984.5 & $2,407.7$ & $4,360.7$ & $2,538.3$ & $2,606.4$ & $2,034.6$ \\
\hline \multirow[t]{5}{*}{$\mathrm{CL} / 1.73 \mathrm{~m}^{2}(\mathrm{~L} / \mathrm{h})$} & Mean & 1.6 & 4.1 & 7.8 & 7.2 & 4.7 & 7.2 & 7.0 & 7.5 \\
\hline & $\mathrm{SD}$ & 0.8 & 1.1 & 1.9 & 1.5 & 0.8 & 2.0 & 2.2 & 1.2 \\
\hline & Median & 1.6 & 4.5 & 8.1 & 7.1 & 5.0 & 6.5 & 6.4 & 7.5 \\
\hline & Min & 0.7 & 2.1 & 5.0 & 5.7 & 3.8 & 5.1 & 5.2 & 6.7 \\
\hline & Max & 3.0 & 5.5 & 9.8 & 10.0 & 5.7 & 9.5 & 10.2 & 8.4 \\
\hline \multirow[t]{5}{*}{$t_{1 / 2}(h)$} & Mean & 12.2 & 5.0 & 3.8 & 11.9 & 8.3 & - & - & - \\
\hline & $\mathrm{SD}$ & 8.6 & 1.0 & 0.3 & 5.9 & 0.7 & - & - & - \\
\hline & Median & 10.1 & 5.1 & 3.8 & 12.4 & 8.5 & - & - & - \\
\hline & Min & 4.1 & 3.7 & 3.5 & 5.6 & 7.5 & - & - & - \\
\hline & Max & 28.5 & 6.7 & 4.4 & 17.4 & 9.1 & - & - & - \\
\hline
\end{tabular}

$A R F$ Acute renal failure

Doses: group 1: $7.5 \mathrm{U} / \mathrm{kg}$, group 2: $22.5 \mathrm{U} / \mathrm{kg}$, group 3: $67.5 \mathrm{U} / \mathrm{kg}$, group 5: $200 \mathrm{U} \mathrm{kg}^{-1} 24 \mathrm{~h}^{-1}$ (24-h infusion), group 8: $67.5 \mathrm{U} / \mathrm{kg}(10 \mathrm{~min})+$ 177.5 $\mathrm{U} \mathrm{kg}^{-1} 24 \mathrm{~h}^{-1}$ (72-h infusion), group 9: 67.5 U/kg (10 min) + 132.5 $\mathrm{U} \mathrm{kg}^{-1} 24 \mathrm{~h}^{-1}$ (24-h infusion)

whether or not patients sustained acute renal failure or received RRT.

\section{Pharmacodynamics evaluations}

There were no changes in any of the pharmacodynamics evaluations in volunteers receiving AP infusions without LPS challenge (groups 1, 2, 3, 5, and 8).

In the groups receiving LPS challenge (groups 4,6 , and 7), a febrile response was observed for up to $8 \mathrm{~h}$ after LPS injection, but there were no differences in body temperature and vital signs between placebo and APtreated volunteers before, during, or after challenge. Body temperature increased $4-8 \mathrm{~h}$ (maximum at $6 \mathrm{~h}$; mean $\pm \mathrm{SD}=2.1 \pm 0.7^{\circ} \mathrm{C}$ ) post-endotoxin, returning to normal within $24 \mathrm{~h}$. Other vital signs followed the pattern of febrile response although the changes were shorter-lived (up to $4 \mathrm{~h}$ post-challenge), returning to baseline thereafter. In the same groups, there was an increase in peripheral blood neutrophil count with relative decreases in eosinophils, basophils, lymphocytes, and monocytes 1-10 $\mathrm{h}$ after LPS injection, all of which were expected post-endotoxin challenge and indistinguishable across treatment groups.

Evaluation of cytokine response in groups 4, 6, and 7 (group 7 displayed in Fig. 3) showed increases in the response of circulating cytokines to endotoxemia as expected (minimally for IL-1 $\beta$ ) but, although mean values of all cytokines' response were lower on AP, there were no significant differences relative to placebo, which suggests that AP may not influence systemic cytokine levels substantially.

In sepsis patients, cytokines exhibited large inter- and intrapatient variability, with no relevant differences being observed among treatment groups. Likewise, no other systemic inflammatory parameters yielded robust or consistent evidence of marked differences among groups that could be considered clinically meaningful; hence these data 

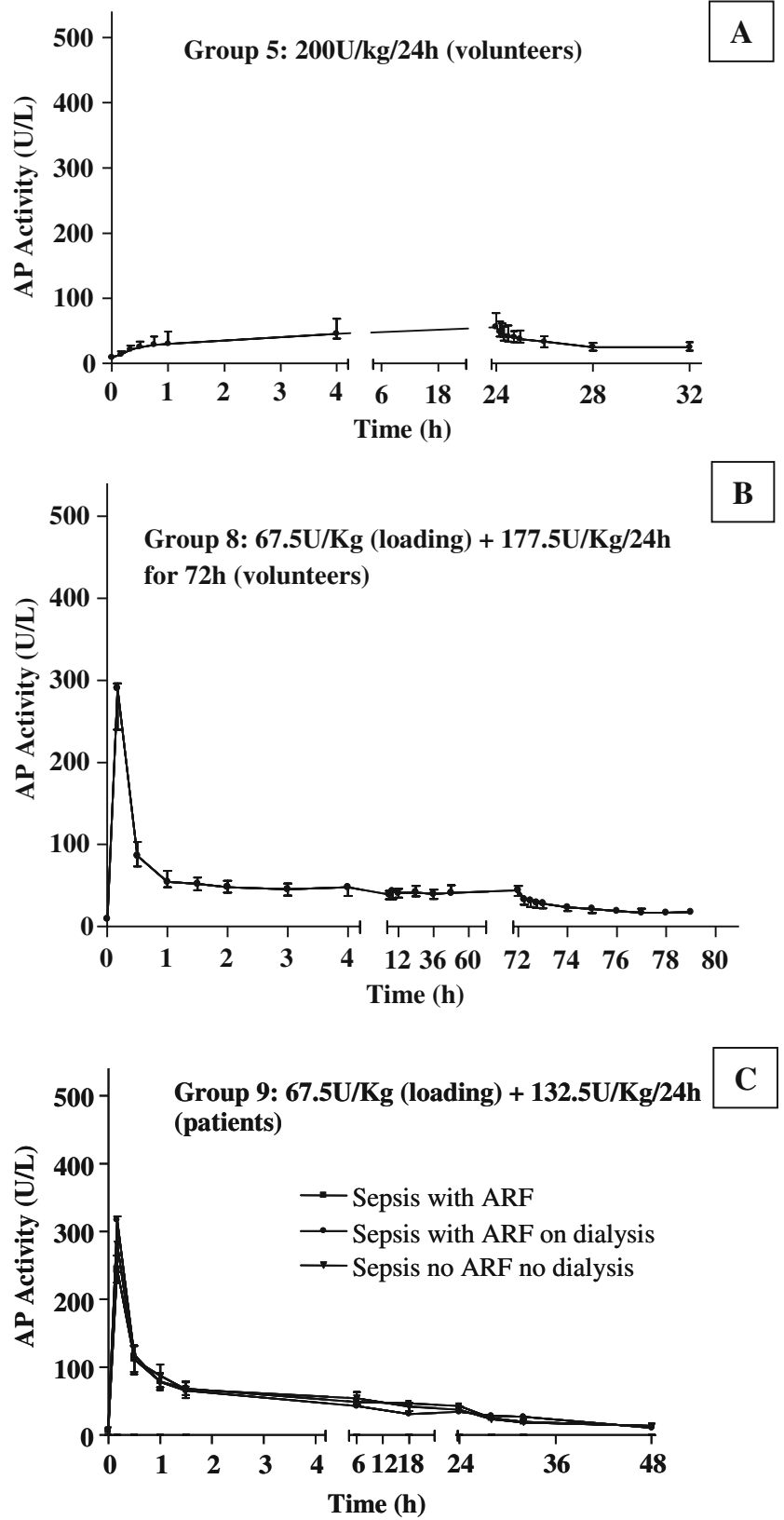

Fig. 2 Mean serum AP activity (long infusions $>24$ h) for groups 5 (a), 8 (b), and 9 (c). Serum activity data points are medians and interquartile ranges. $A R F$ Acute renal failure

are not tabulated. Plasma lactate was significantly lower in AP-treated patients on days 2 and 4 after treatment $(P<$ $0.04)$, but the relevance of this finding in the absence of other changes in systemic inflammatory markers is uncertain. Differences in pharmacodynamics between treatment groups were confined to clinical outcomes related to acute renal failure as previously reported [18], with all-cause mortality rates of 60 and $27 \%$ on placebo and AP, respectively, while dialysis intervention was required in 80 and $36 \%$ of patients, respectively. The parameters related to acute kidney injury were in line with clinical outcomes and have been reported elsewhere [18], with serum creatinine and cumulative urinary excretion of GSTA11 being considerably lower in AP-treated patients and correlating with $\mathrm{NO}$ metabolite excretion $\left(\mathrm{r}_{\mathrm{s}}=0.5 ; P<0.01\right)$.

Safety results

The main adverse events from the safety evaluations are presented in Table 4. Exogenous administration of AP did not raise safety concerns in volunteers or sepsis patients. In volunteers, the most common event was headache, reported both on placebo $(65 \%)$ and on AP $(40 \%)$. In sepsis patients, the most frequently reported event was "general condition aggravated," reported by $18 \%$ on placebo and $12 \%$ on AP.

No antibodies against AP were detected (specific IgGanti-AP, total immunoglobulins, or $\operatorname{IgE}$ ) in volunteers or patients up to 21 days post-administration, while skin-prick tests were negative in volunteers and, consequently, not evaluated in patients. Clinical laboratory (hematology, biochemistry, urinalysis) and 12-lead ECGs (including QTinterval) did not suggest treatment-related abnormalities.

Challenge with LPS endotoxin in volunteers was associated with myalgia and rigors, similarly on placebo and AP (Table 4). The tolerability of exogenous AP in patients with circulating endotoxins was subsequently confirmed in group 9 (sepsis patients).

\section{Discussion}

Knowledge of clinical pharmacology of drugs in patients with sepsis is scarce despite profound sepsis-induced pathophysiological changes in these patients often affecting drug absorption, distribution, metabolism, and excretion [19]. Mammalian APs are membrane-bound enzymes; and in humans, four AP isoenzymes exist of which three are tissue-specific (placental, PLAP; germ cell, GCAP; and intestinal, IAP) and one is tissue nonspecific (TNAP) and is expressed in virtually all tissues (e.g., bone, liver, and kidney). This hydrolase removes phosphate groups from pro-inflammatory molecules [8-12], dephosphorylation being a key mechanism in host defense against inflammation, whether due to exogenous toxins such as bacterial LPS or to endogenous extracellular ATP [20,21], the latter having a potent pro-inflammatory activity [22]. AP administration may enhance endogenous dephosphorylating capacity when the need is greatest, such as during acute inflammatory response, to reduce local tissue damage and to retain organ function. Animal models of sepsis have shown exogenous AP to attenuate the inflammatory response and to improve tissue damage and outcomes [16, 23] 
Fig. 3 Changes in cytokines after LPS challenge (group 7). Solid lines indicate alkaline phosphatase $(n=6)$; hashed lines indicate placebo $(n=4)$. Time 0 is the start of 2-min LPS challenge. Cytokine values at each time point are arithmetic means
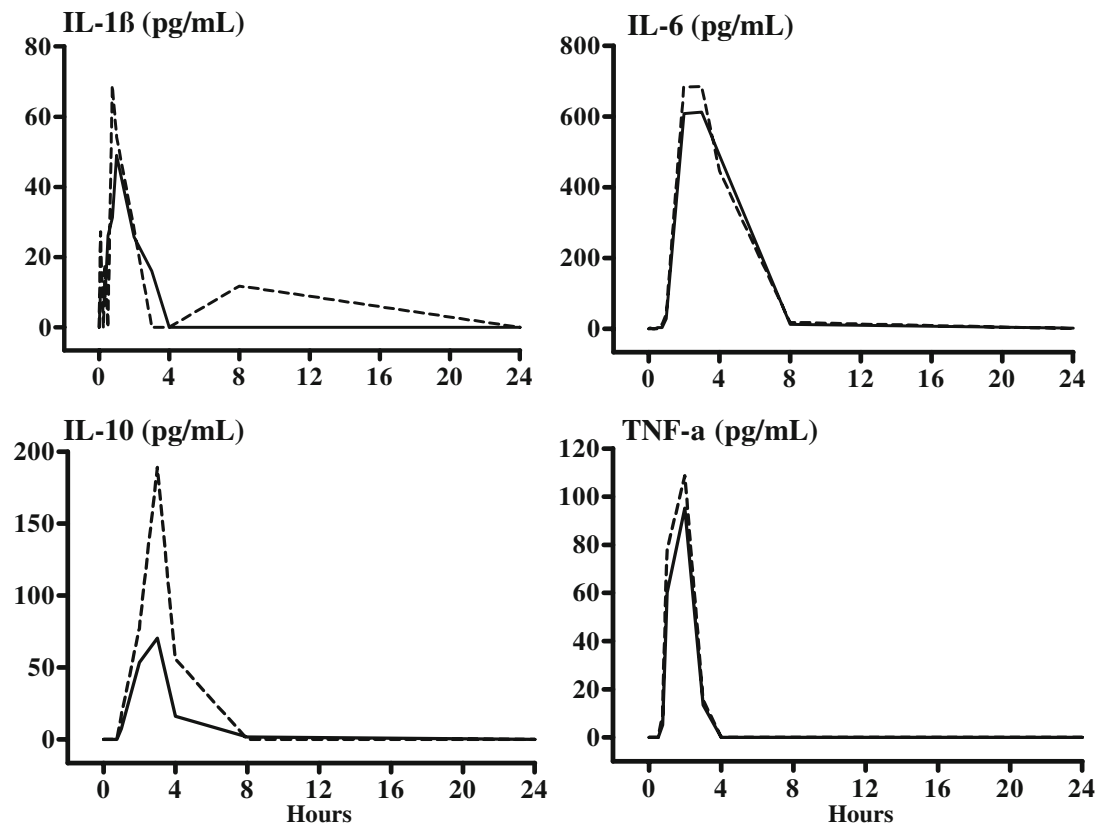

LEGEND:

Solid lines $=$ alkaline phosphatase $(n=6) ;$ Hashed lines $=$ placebo $(n=4)$

Time 0: start of 2-minute LPS challenge

Cytokine values at each time -point are arithmetic means

Evaluation of the pharmacokinetics of exogenous AP in humans is complex because the enzyme is also produced endogenously and the activities of endogenous and exogenous enzymes are indistinguishable. We corrected enzyme values for pre-dosing activity, although this does not completely exclude interference from endogenous variations due to circadian and food influences. We controlled endogenous interference in volunteers through fasting, bearing in mind that it is impossible to totally abolish interference from endogenous enzyme physiologically or in pathology. Therefore, while $\mathrm{C}_{\max }$ and AUC of short infusions with low doses of AP showed linearity of enzyme activity in relation to dosing, short infusions were poor predictors of elimination and clearance during long infusions. Nevertheless, the linearity and dose-proportionality of AUCs after administration of ascending doses of exogenous enzyme demonstrate that the AUC is related to exogenous enzyme administration.

We also found during the dose escalation that to achieve (over a period of at least $24 \mathrm{~h}$ ) approximately double the baseline level of endogenous enzyme activity, a loading dose is required, without which the ascending activity curve is too shallow to yield end-organ-protective enzyme levels for the metabolic assault of LPS or extracellular ATP expected in sepsis. This was corroborated by our patient data suggesting that exogenous AP may affect local endorgan parameters (kidney) and related clinical outcomes but not systemic markers of inflammatory response (circulating cytokines). The estimation of ideal serum activity is all the more complex because the accepted normal range of AP in serum is too wide to reflect the values we found in our volunteers and patients. The literature refers to $20-200 \mathrm{U} / \mathrm{L}$ AP serum activity [24, 25], yet the top-end of normal is justified but not typically observed except after food, alcohol, and other "normal" activities, whereas abnormal levels tend to be multiples of the upper limit of normal. There is no evidence from literature that high levels of AP are harmful per se, enzyme level denoting tissue effort to repair damage rather than the enzyme itself being toxic or damaging $[26,27]$.

Our data suggest that relatively stable serum AP activity can be achieved at a level that is approximately double that of endogenous enzyme for a period of 24-72 $\mathrm{h}$ by administering a loading dose of $67 \mathrm{U} / \mathrm{kg}$ followed by a continuous infusion of $132-177 \mathrm{U} \mathrm{kg}^{-1} 24 \mathrm{~h}^{-1}$, due to fast elimination time, which for a $140-\mathrm{kD}$ protein reflects metabolism rather than excretion. Our data also show that, without a loading dose, it is not possible to increase serum enzyme activity substantially within $24 \mathrm{~h}$, which is an important factor in acute intervention, e.g., in sepsis patients. Importantly, the safety data from 103 subjects in our studies do not suggest that exogenous AP causes any detectable adverse effects in humans in the dose range we tested. 
Table 4 Safety and tolerability data $(n=103)$

\begin{tabular}{|c|c|c|}
\hline & Placebo, $n(\%)$ & $\mathrm{AP}, n(\%)$ \\
\hline Groups $1-8$ (healthy volunteers) & $(n=17)$ & $(n=50)$ \\
\hline All adverse events & 46 & 93 \\
\hline Subjects with reported events & $11(65 \%)$ & $27(54 \%)$ \\
\hline Serious adverse events & 0 & 0 \\
\hline \multicolumn{3}{|l|}{ Events reported in $>1$ volunteer } \\
\hline Headache & 11 & 20 \\
\hline Rigors & 7 & 11 \\
\hline Dizziness & 5 & 7 \\
\hline Nausea/vomiting & 4 & 7 \\
\hline Back pain & 3 & 4 \\
\hline Feeling cold & - & 4 \\
\hline Feeling hot & 1 & 4 \\
\hline Fatigue & 1 & 3 \\
\hline Nasal congestion & - & 3 \\
\hline Flu-like illness & - & 2 \\
\hline Injection-site reaction & - & 2 \\
\hline Myalgia & 2 & 2 \\
\hline Group 9 (sepsis patients) & $(n=11)$ & $(n=25)$ \\
\hline Adverse events ${ }^{\mathrm{a}}$ & 16 & 34 \\
\hline Patients with reported events & $7(64)$ & $17(68)$ \\
\hline Serious adverse events $(\mathrm{SAE})^{\mathrm{b}}$ & $7(64)$ & $10(40)$ \\
\hline Treatment-related $\mathrm{SAE}^{\mathrm{c}}$ & $3(27)$ & - \\
\hline Death (all-cause) & $4(36)$ & $6(24)$ \\
\hline Treatment-related death ${ }^{\mathrm{c}}$ & $1(9)$ & - \\
\hline \multicolumn{3}{|l|}{ Events reported in $>1$ patient } \\
\hline General condition aggravated & 2 & 3 \\
\hline Herpes simplex & 1 & 2 \\
\hline Atrial fibrillation & 3 & - \\
\hline Increased liver enzyme & - & 2 \\
\hline Pruritus & - & 2 \\
\hline Troponin increased & - & 2 \\
\hline Sepsis aggravated & 2 & - \\
\hline
\end{tabular}

${ }^{a}$ Includes multiple events in one patient, considered possibly or definitely treatment-related

${ }^{\mathrm{b}}$ Life-threatening, or causing death or prolongation of hospitalization ${ }^{\mathrm{c}}$ Reported blindly (before code-break) by physician as possibly treatment-related

The results also show that the pharmacokinetics of exogenously administered AP is similar in volunteers and patients, not altered substantially, if at all, by the presence of systemic inflammation in severe sepsis with or without acute renal failure and, although data on dialysis patients were limited, there was no indication of any differences in this subset.

The current characterization of the clinical pharmacology parameters of exogenous AP is complex due to AP being part of human economy, but it was paramount to enable further research of this enzyme in the treatment of acute renal failure in sepsis and other clinical settings where extracellular ATP and/or LPS play a role, such as in postoperative vascular-origin acute renal failure and inflammatory bowel disease, where there is an urgent need for effective treatments. However, there are limitations on the use of animal-origin enzyme, due to difficulties in obtaining bovine enzyme from BSE-free sources and the risk of immune reactions after repeated exposure. Although we did not detect antibody formation in volunteers or patients, it is highly likely that animal-sourced AP will elicit immune reactions if repeated or given for longer periods [28]. We are advised by the manufacturers that a recombinant human form of AP will become available shortly, which will allow repeated administration in future. Until such time intravenous AP should be tried as a onceonly treatment.

\section{Conclusions}

Exogenous intravenous administration of AP enzyme exhibits linear kinetics and dose proportionality during short infusions in the dose range $22.5-67.5 \mathrm{U} / \mathrm{kg}$. Continuous IV infusions of exogenous AP in the range 132.5$177.5 \mathrm{U} \mathrm{kg}^{-1} 24 \mathrm{~h}^{-1}$ preceded by a loading dose of $67.5 \mathrm{U} / \mathrm{kg}$ can achieve relatively stable serum enzyme activity over periods of 24-72 $\mathrm{h}$ that are approximately twice the level of endogenous enzyme. Clearance of exogenous AP given as continuous infusion is in the range $5.2-7.5 \mathrm{~L} / \mathrm{h}$, and elimination half-life is $8-12 \mathrm{~h}$ in humans. While the data we accrued provide clinical pharmacology parameters for larger therapeutic trials, preliminary data from patients suggest that exogenous AP administration in severe sepsis patients may play a renal protective role, possibly via dephosphorylation of extracellular ATP and LPS, that is worth further clinical investigation.

Acknowledgements The authors are grateful to Jennifer Schwamborn (CRM Biometrics), Willem Raaben, and Marty Wulferink (AM-Pharma BV) for their help in compiling the data for the manuscript, and to the nursing teams of all participating hospitals for their help with data collection.

Funding The studies were funded by AM-Pharma BV, Bunnik, The Netherlands, who also provided active and placebo AP enzyme for the studies.

Conflict of interest None declared. Protocols for studies A and B were designed by the sponsor (AM-Pharma B.V.) and the protocol for study $\mathrm{C}$ was designed in conjunction with the intensive care units involved in the study. Monitoring and auditing of the studies were conducted externally by SGS Life Sciences Services, Antwerp, Belgium. Statistical analyses were conducted externally by CRM Biometrics, Rheinbach, Germany.

Open Access This article is distributed under the terms of the Creative Commons Attribution Noncommercial License which permits any noncommercial use, distribution, and reproduction in any medium, provided the original author(s) and source are credited. 


\section{References}

1. McComb RB, Bowers GN Jr, Posen S (eds) (1979) Alkaline phosphatases. Plenum Press, New York

2. O'Brien PJ, Herschlag D (2001) Functional interrelationships in the alkaline phosphatase superfamily: phosphodiesterase activity of Escherichia coli alkaline phosphatase. Biochemistry 40 (19):5691-5699

3. Yang C, Kong J, Wang Q, Liu Q, Tian Y, Luo K (2007) Heterosis of haemolymph analytes of two geographic populations in Chinese shrimp Fenneropenaeus chinensis. Fish Shellfish Immunol 23(1):62-70

4. Millán JL (2006) Alkaline phosphatases: structure, substrate specificity and functional relatedness to other members of a large superfamily of enzymes. Purinergic Signal 2(2):335-341

5. Harris H (1990) The human alkaline phosphatases: what we know and what we don't know. Clin Chim Acta 186:133-150

6. Anonymous (1961)IntEnz enzyme nomenclature. EC 3.1.3.1: Alkaline phosphatase, of phosphoric monoester hydrolases (EC 3.1.3), of acting on ester bonds (EC 3.1), of hydrolases (EC 3). http://www.ebi.ac.uk/intenz/query? cmd=SearchID\&id=3276. Accessed 20 Nov 2008

7. Stigbrand T, Millán JL, Fishman WH (1982) The genetic basis of alkaline phosphatase isozyme expression. Isozymes Curr Top Biol Med Res 6:93-117

8. Ohta A, Sitkovsky M (2001) Role of G-protein-coupled adenosine receptors in downregulation of inflammation and protection from tissue damage. Nature 414(6866):916-920

9. Picher M, Burch LH, Hirsh AJ, Spychala J, Boucher RC (2003) Ecto 5'-nucleotidase and nonspecific alkaline phosphatase. Two AMP-hydrolyzing ectoenzymes with distinct roles in human airways. J Biol Chem 278(15):13468-13479

10. Le Hir M, Angielski S, Dubach UC (1985) Properties of an ecto-5'nucleotidase of the renal brush border. Ren Physiol 8(6):321-327

11. Yamane K, Maruo B (1978) Alkaline phosphatase possessing alkaline phosphodiesterase activity and other phosphodiesterases in Bacillus subtilis. J Bacteriol 134(1):108-114

12. Vaishnava S, Hooper LV (2007) Alkaline phosphatase: keeping the peace at the gut epithelial surface. Cell Host Microbe 2(6):365-367

13. Malo MS, Biswas S, Abedrapo MA, Yeh L, Chen A, Hodin RA (2006) The pro-inflammatory cytokines, IL-1beta and TNF-alpha, inhibit intestinal alkaline phosphatase gene expression. DNA Cell Biol 25(12):684-695

14. Anonymous (1997) World Health Organization, International Conference on Harmonization, topic E6. Guideline for good clinical practice. US Fed Reg 62(90):25691-25709E7. http://www. ich.org/LOB/media/MEDIA482.pdf. Accessed 20 Nov 2008

15. Bone RC, Balk RA, Cerra FB, Dellinger RP, Fein AM, Knaus WA, Schein RM, Sibbald WJ (1992) Definitions for sepsis and organ failure and guidelines for the use of innovative therapies in sepsis.
The ACCP/SCCM Consensus Conference Committee. American College of Chest Physicians/Society of Critical Care Medicine. Chest 101:1644-1655

16. Beumer C, Wulferink M, Raaben W, Brands R, Seinen W (2003) Calf intestinal alkaline phosphatase (CIAP), a novel therapeutic drug for LPS-mediated diseases, attenuates LPS toxicity in mice and piglets. J Pharmacol Exp Ther 307:737-744

17. European Medicines Agency 92004) Note for guidance on minimizing the risk of transmitting animal spongiform encephalopathy agents via human and veterinary medicinal products (EMEA/410/01 rev.2). http://www.emea.europa.eu/pdfs/human/ bwp/TSE\%20NFG\%20410-rev2.pdf. accessed 20 Nov 2008

18. Heemskerk S, Masereeuw R, Moesker O, Bouw MPWJM, van der Hoeven JG, Peters WHM, Russel FGM, Pickkers P (2007) Alkaline phosphatase treatment improves renal function in patients with severe sepsis or septic shock. Crit Care 11(Suppl 2): P14

19. De Paepe P, Belpaire FM, Buylaert WA (2002) Pharmacokinetic and pharmacodynamic considerations when treating patients with sepsis and septic shock. Clin Pharmacokinet 41(14):1135-1151

20. Bours MJL, Swennen ELR, Di Virgilio F, Cronstein BN, Dagnelie PC (2006) Adenosine 5'-triphosphate and adenosine as endogenous signalling molecules in immunity and inflammation. Pharmacol Ther 112:358-404

21. Ohta A, Sitkovsky M (2001) Role of G-protein-coupled adenosine receptors in downregulation of inflammation and protection from tissue damage. Nature 414(6866):916-920

22. Picher M, Burch LH, Hirsh AJ, Spychala J, Boucher RC (2003) Ecto 5'-nucleotidase and non-specific alakaline phosphatase. Two AMO-hydrolysis ectoenzymes with distinct roles in human airways. J Biol Chem 278(15):13468-13479

23. Su F, Brands R, Wang Z, Verdant C, Bruhn A, Cai Y, Raaben W, Wulferink M, Vincent JL (2006) Beneficial effects of alkaline phosphatase in septic shock. Crit Care Med 34(8):2182-2187

24. General Practice Notebook (2008) UK medical reference for general practitioners: reference range for alkaline phosphatase (30-200U/L). http://www.gpnotebook.co.uk/simplepage.cfm? ID $=302383171 \&$ linkID=1068\&cook=no. Accessed 20 Nov 2008

25. MedLine Plus (2008) Medical encyclopaedia: ALP isoenzyme test range: $20-140 \mathrm{U} / \mathrm{L}$. http://www.nlm.nih.gov/medlineplus/ency/article/ 003497.htm\#Normal\%20Values. Accessed 20 Nov 2008

26. Tung CB, Tung CF, Yang DY, Hu WH, Hung DZ, Peng YC, Chang CS (2005) Extremely high levels of alkaline phosphatase in adult patients as a manifestation of bacteremia. Hepatogastroenterology 52(65):1347-1350

27. Maldonado O, Demasi R, Maldonado Y, Taylor M, Troncale F, Vender R (1998) Extremely high levels of alkaline phosphatase in hospitalized patients. J Clin Gastroenterol 27(4):342-345

28. Delves PJ, Martin S, Burton D, Roitt I (eds) (2006) Roitt's essential immunology, 11th ed. Chapter 5: the primary interaction with antigen. Blackwell, Malden 